\title{
ASPECTOS GERAIS DA CONSTRUÇÃO DE UM PROGRAMA SOBRE COMUNICAÇÃO NÃO VERBAL PARA ENFERMEIROS*
}

\author{
Maria Júlia Paes da Silva**
}

SILVA, M. J. P. da. Aspectos gerais da construção de um programa sobre comunicação não verbal para enfermeiros. Rev.latino-am.enfermagem, Ribeirão Preto, v. 4, nº especial, p. 25-37, abril 1996.

Este trabalho apresenta um programa sobre comunicação não verbal e é continuação de um estudo onde se verificaram falhas na percepção desse tipo de comunicação nos enfermeiros que atendiam pacientes em consultas de enfermagem. É um dos primeiros estudos que discute a temática do ensino da comunicação não verbal na enfermagem e justifica sua montagem descrevendo rapidamente 0 referencial teórico que embasou sua montagem: LUFT \& INCHAM (1961); BIRDWHISTELL (1970); HALL (1986); STEINBERG (1988); SILVA (1989) e CAGNÉ (1980).

UNITERMOS: comunicação, comunicação não verbal

\section{INTRODUÇÃO}

O meu interesse pela comunicação não verbal surgiu quando, ainda enfermeira assistencial, percebi que apesar da comunicação verbal entre enfermeira-paciente ocorrer de acordo com o conteúdo pré-estabelecido pela instituição nas consultas de enfermagem realizadas, ou seja, de acordo com as normas e padrões considerados

\footnotetext{
* Extraído da Tese de Doutorado da autora "Construção e validação de um programa sobre comunicação não verbal para enfermeiros", sob orientação da Prof. Dr. Maguida Costa Stefanelli

** Enfermeira. Professor Doutor do Departamento de Enfermagem Médico-Cirúrgica da Escola de Enfermagem da Universidade de São Paulo - COREn 15448- São Paulo
} 
satisfatórios, muitas vezes, pacientes que tiveram alta hospitalar em ótimas condições de recuperação, retornavam ao hospital em pior estado de saúde do que na internação anterior.

$\mathrm{Na}$ interação com alguns destes pacientes, ficava claro que os motivos que provocaram a recidiva da sua situação clínica poderiam ser explicados por falhas na comunicação do pessoal de saúde que os orientou.

Várias dúvidas me surgiram sobre onde estaria a falha nas orientações, já que o seu conteúdo estava completo, ou mesmo se os enfermeiros estariam cientes do seu papel de comunicadores, da importância da coerência entre comunicação verbal e não verbal.

A comunicação não verbal pode ser definida como a que inclui todas as formas e comunicação que não envolvam as palavras expressas ${ }^{1,2,3,8,13}$. Ela envolve todos os órgãos do sentido ${ }^{4,8}$ e ocorre na interação pessoa-pessoa mesmo que não haja verbalização de palavra alguma. Ou seja, quando é aceito e entendido que todo comportamento, numa situação interacional tem valor de mensagem, entendemos que o indivíduo pode deixar de verbalizar algo ao outro, mas não deixa de se comunicar através da expressão facial, postura corporal, distância mantida entre outros ${ }^{5,20}$.

Lembram, os autores, que os enfermeiros estão se esquecendo de que os pacientes interpretam nossas mensagens não apenas pelo que dizemos, mas pelo que fazemos s, $^{2,5,10,19}$.

Os autores consultados consideram que um terço do significado das mensagens é transmitido pela comunicação verbal e dois terços pela comunicação não verbal ${ }^{1,5}$. DAVIS ${ }^{4}$ chega a afirmar que 55 a $65 \%$ das mensagens recebidas provêm da comunicação não verbal, pois apesar de uma pessoa ser capaz de falar aproximadamente 150 palavras por minuto, o cérebro é capaz de processar muito mais informações nesse período.

A comunicação não verbal utiliza três espécies de suporte: o corpo (nas suas qualidades físicas, fisiológicas e nos movimentos); os artefatos usados pelo homem ou ligados ao meio ambiente (ambos produtos da habilidade humana que servem à comunicação); e a disposição dos indivíduos no espaço ${ }^{3}$.

Os tipos de sinais não verbais são, portanto: as ações ou movimentos corpóreos, o toque, a postura corporal, os sinais vocais, o espaço entre os comunicadores, os objetos e adornos utilizados, o tipo de corpo das pessoas envolvidas no processo comunicativo e o momento em que as palavras são ditas.

Os autores pesquisados, apesar de subdividirem de maneira diferente os sinais não verbais, concordam que comunicação não verbal é tudo que pode ter significado para o emissor ou o receptor, exceto as palavras por elas mesmas.

Um aspecto importante da comunicação não verbal é que ela não pode ser interpretada fora do contexto em que ocorreu, pois o significado da mensagem pode variar ao longo da história, das culturas e do momento, sendo ambígua várias vezes $^{1,2,3,5,8,13,18}$. Ela precisa ser estudada justamente para poder ser compreendida corretamente, além de seu estudo permitir que o enfermeiro efetive sua comunicação interpessoal. 
Ao aceitar a premissa que a enfermagem é um processo interpessoal, também assumi o compromisso de desenvolver mais pesquisas sobre comunicação, no intuito que estas pudessem contribuir efetivamente para solidificar cada vez mais os conhecimentos da enfermagem.

PELÁ et al ${ }^{12}$ mostram que $20 \%$ (18) dos trabalhos científicos da pós-graduação da Escola de Enfermagem de Ribeirão Preto da Universidade de São Paulo são na linha educativa, sendo que destes $20 \%$, apenas $11 \%$ (2) se referem à educação da equipe de enfermagem. As autoras notam ser necessário que as propostas educativas feitas pelos trabalhos sejam implementadas e avaliadas, para que possam modificar realmente a prática existente. "Desta forma, os futuros trabalhos no campo de educação em saúde passarão de 'diagnósticos' das necessidades de informação para análise das mudanças ocorridas na clientela após implementação do processo ensino-aprendizagem".

$\mathrm{Na}$ minha monografia de mestrado, foi investigada a percepção das enfermeiras a respeito da comunicação, na interação com os pacientes e, principalmente, a percepção sobre a comunicação não verbal dos mesmos, além de verificar se as enfermeiras estavam validando a comunicação não verbal emitida por eles. Observou-se que a percepção das enfermeiras, a respeito da comunicação na interação com os pacientes, é voltada para a comunicação verbal. Sendo também apontado por elas, vários dos aspectos considerados importantes pela bibliografia consultada. Pode ser constatado, que a percepção das enfermeiras sobre a comunicação não verbal dos pacientes estava falha no nível consciente, dificultando, portanto, o processo de validação da comunicação não verbal ${ }^{14}$.

Notou-se ainda, nas respostas das enfermeiras, que a comunicação é entendida principalmente de forma verbal, pois usaram no seu discurso os seguintes termos para explicá-la: "falar mais", "conversa", "linguagem", "perguntas", "contar", que direcionam o seu entendimento para o tipo de comunicação verbal. O reforço para esta afirmação veio também do baixo número de citações de sinais não verbais captados por elas de maneira consciente e registrados nas categorias solicitadas pela pesquisadora. 0 número de sinais não verbais percebidos por elas atingiu a média de 2,5 sinais por consulta de enfermagem em relação à média de 43 sinais não verbais por consulta, percebidos pela pesquisadora ${ }^{14}$.

Com esse resultado concluiu-se que a baixa percepção dos sinais não verbais dos pacientes pelos enfermeiros, pode estar influindo no número de retornos de pacientes em piores condições de saúde, pois falhas no processo comunicativo interferem na compreensão das orientações recebidas pelos pacientes. A título de contribuição, foram, também, traçados os componentes gerais de um programa sobre comunicação não verbal que pudessem ser utilizados na educação continuada dos enfermeiros da instituição.

Acredito, também, que a educação continuada é a única maneira que os membros da equipe de enfermagem de um hospital têm para se manter atualizados e competentes na sua prática. Com as mudanças tecnológicas e científicas acontecendo rapidamente, cada vez mais se toma importante a discussão de métodos e programas nesta área ${ }^{9,17}$. Porém, os programas devem ser montados a 
partir de necessidades reais sentidas pelos enfermeiros, para que possam gerar uma mudança de comportamento e atingir, também, os objetivos da instituição ${ }^{9,17}$.

Neste artigo apresento apenas o programa utilizado para o desenvolvimento

da pesquisa de doutorado ${ }^{16}$ e o referencial teórico que o embasou. Os resultados de sua aplicação e a discussão pertinente encontram-se registrados na tese.

\section{QUADRO TEÓRICO DE REFERÊNCIA DO PROGRAMA}

A visão de mundo de cada pessoa, de cada pesquisador, reflete-se no modo de conduzir o processo da investigação científica; por outro lado, esse processo está mediado por condições sociais, institucionais e científicas que determinam a sua produção.

Com esta compreensão é que selecionei os autores que referendam os vários aspectos envolvidos com o problema em questão, ou seja, a construção de um programa sobre comunicação não verbal viável para a utilização pelo setor da educação continuada, sempre necessário.

O esquema I, apresentado a seguir, é uma representação gráfica do referencial teórico utilizado.

\section{ESQUEMA I - REPRESENTAÇÃO GRÁFICA DO REFERENCIAL TEÓRICO}

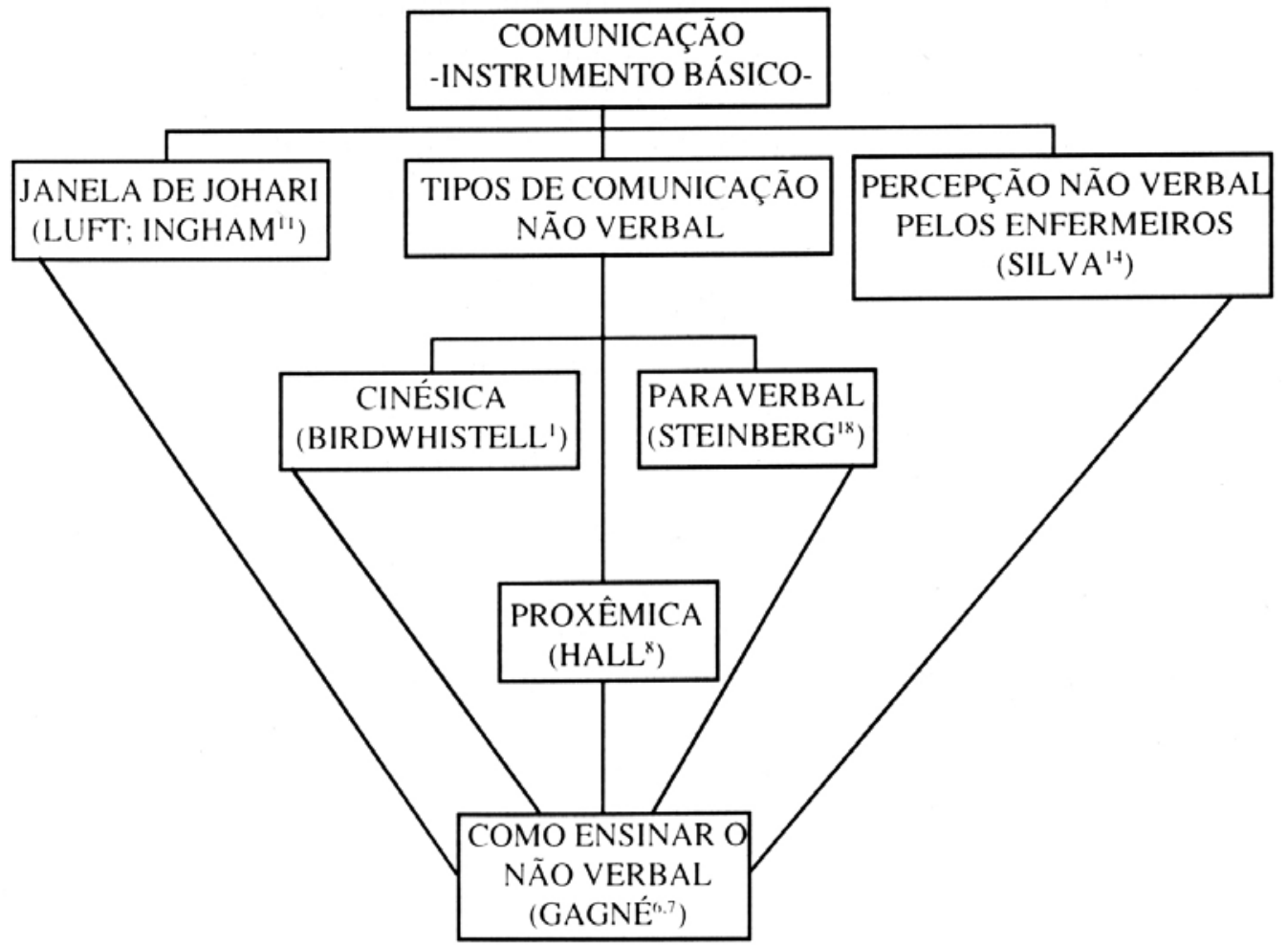


O modelo de interação humana desenvolvido por LUFT; INGHAM ${ }^{11}$, denominado de "A Janela de Johari", explica a complexidade da personalidade humana, especialmente em suas relações com os outros. Os autores propõem que o comportamento humano deve ser abordado de um modo holístico; a sua análise deve ser contextual; o que está acontecendo de uma pessoa é melhor entendido subjetivamente, em termos das percepções e dos sentimentos do indivíduo; o comportamento é primordialmente emocional, não racional; a tendência da pessoa é não ter clara todas as fontes do seu próprio comportamento.

A Janela de Johari ${ }^{11}$ chama a atenção para aspectos conhecidos da pessoa e os que estão fora de sua percepção consciente. O importante, do ponto de vista da comunicação, é que enfatiza as mudanças de percepção consciente que ocorrem com o passar do tempo.

BIRDWHISTELL ${ }^{1}$ é o inventor do neologismo cinésica, sendo considerado o pioneiro nesta área. Usou a lingüística como modelo para sua obra onde estudou os sinais do corpo a partir de uma estruturação semelhante à usada para a compreensão da fala humana.

Entre os pressupostos básicos nos quais baseou sua teoria ${ }^{1}$, considera-se importante ressaltar que nenhum movimento ou expressão corporal é destituído de significado no contexto em que se apresenta; tal como outros aspectos do comportamento humano, a postura corporal, o movimento e a expressão facial são padronizados e, por conseqüência, sujeitos à análise sistemática; embora sejam reconhecidas as possíveis limitações impostas por substratos biológicos particulares, até que seja demonstrado o contrário, o movimento corporal sistemático das pessoas de uma comunidade é considerado uma função do sistema social a que o grupo pertence; a atividade corporal visível, assim como a atividade fonética audível, influencia o comportamento de outros membros de qualquer grupo.

Além dessas idéias centrais, BIRDWHISTELL ${ }^{1}$ afirma que a comunicação faz uso de todos os canais sensoriais humanos e que, embora seja importante desenvolver métodos para estudar cada canal, o pesquisador deve estar sempre atento ao todo.

$\mathrm{HALL}^{8}$ é o pioneiro no estudo da proxêmica, assim com BIRDWHISTELL ${ }^{1}$ o é da cinésica. Afirma que existe uma relação entre o uso dos sentidos na interação e as distâncias interpessoais. Proxêmica é, portanto, um neologismo criado por ele, para designar o conjunto das observações e teorias referentes ao uso que o homem faz do espaço enquanto produto cultural específico.

O autor $^{8}$ definiu oito fatores possíveis de serem estudados na análise proxêmica de uma interação: fatores de postura-sexo (sexo dos participantes e posturas básicas); eixo sociófugo-sociópeto (refere-se ao ângulo formado pelos ombros em relação a outra pessoa); fatores cinestésicos (proximidade dos indivíduos em termos de possibilidade de contato físico); comportamento de contato (modalidades do tocar no outro); código visual (modo do contato através da.visão); código térmico (envolve o calor percebido do outro); e, o volume de voz (volume e intensidade da fala). 
Nessa compreensão teórica, o homem e suas extensões (os espaços ao seu redor) não constituem senão um único e mesmo sistema. É um erro tratar o homem à parte, como se ele constituísse uma realidade distinta de sua habitação, local onde se encontra, ou mesmo de sua linguagem. Deve-se aprender a decifrar as mensagens "silenciosas" (não verbais) com tanta facilidade como as comunicações escritas ou faladas.

Para compreender os sinais paraverbais da fala dos pacientes e ter o respaldo teórico necessário para classificá-los como sinais que demonstrassem emoções (surpresa, medo, dúvida, entre outros), foi utilizado o livro. "Os elementos não verbais da conversação" de STEINBERG ${ }^{18}$. Ela estudou os elementos não verbais que acompanham a fala numa interação face-a-face, demonstrando que além da emoção, por meio da para linguagem se pode apontar até o nível social do falante.

Para a classificação dos sinais não verbais de uma maneira geral, utilizei o mesmo referencial desenvolvido no trabalho de mestrado ${ }^{14}$. Quando se tratou especificamente da decodificação dos sentimentos percebidos, foi utilizado também outro estudo da autora ${ }^{15}$, atualizando-se o levantamento feito em 1989.

Na compreensão do que é aprendizagem e como esta poderia ser verificada, já que todo programa precisa ser avaliado, foram utilizados como referencial, os livrostextos de GAGNÉ ${ }^{6,7}$. Segundo esse autor ${ }^{6}$ aprendizagem é um processo que torna alguns organismos vivos capazes de modificar seu comportamento de maneira relativamente rápida, de uma forma mais ou menos permanente, de tal modo que não tenha que ocorrer freqüentemente, em cada nova situação. Um observador externo pode reconhecer que houve aprendizagem quando percebe a ocorrência da mudança comportamental e também a permanência desta mudança.

O processo de aprendizagem, segundo esse autor ${ }^{7}$, ocorre da seguinte forma: a estimulação proveniente do ambiente do aprendiz afeta seus receptores e penetra no sistema nervoso, através de um registrador sensorial. Esta é a estrutura responsável pela recepção inicial de objetos e eventos que o aprendiz vê, ouve ou sente. A informação é detectada no registrador sensorial e ao entrar na memória de breve duração a informação é novamente codificada, desta vez de uma forma conceptual. A permanência na memória de breve duração é relativamente curta e se houver, futuramente, necessidade de se acionar ou lembrar a informação, ela é de novo transformada e passa a se integrar à memória de longa duração, onde é armazenada para posterior rememorização.

A informação proveniente tanto da memória de breve duração quanto da memória de longa duração passa para um gerador de resposta, que tem a função de transformar a informação em ação.

É importante registrar que a necessidade desta abordagem de comunicação não verbal para enfermeiros da instituição, campo da pesquisa, foi validada também pelo fato de o estudo, feito anteriormente pela pesquisadora ${ }^{14}$, comprovar o baixo índice de percepção apresentado pelos enfermeiros em relação aos sinais não verbais dos pacientes. 
A seguir, será apresentado o programa utilizado com seus objetivos, conteúdo e estratégias.

\section{PROGRAMA SOBRE COMUNICAÇÃO NÃO VERBAL}

\section{Objetivos do programa}

Ao final do programa o enfermeiro deverá:

1. discorrer sobre o que é a comunicação não verbal e sua importância nas relações interpessoais;

2. apontar exemplos de sinais não verbais possíveis de serem detectados nas relações enfermeiro-paciente;

3. enumerar fatores que interferem na percepção adequada da comunicação não verbal ;

4. aplicar seu conhecimento de sinais não verbais em situação simulada e real de interação enfermeiro-paciente, distinguindo-os de acordo com sua finalidade;

5. passar a valorizar a comunicação não verbal sua e do paciente.

\section{Conteúdo Programático}

e

Estratégia Utilizada
- Introdução com breve explicação do
processo geral de comunicação, sua
definição e comunicação como
processo e como instrumento de
trabalho do enfermeiro. Definir
comunicação verbal e resgatá-la como
elemento que pode auxiliar na
expressão, clarificação e validação da
comunicação com o paciente.

- Conceito e importância da comunicação não verbal, sua relação com a comunicação verbal e porcentagem que lhe é atribuída numa interação face-a-face. Ressaltar seu valor para a efetivação da comunicação do enfermeiro e para a compreensão correta da mensagem emitida pelo paciente.
Exposição

dialogada

Exposição

dialogada 
- Como ocorre o processo de percepção e compreensão da realidade nas pessoas. $O$ uso dos cinco sentidos no processo de reconhecimento da realidade, sua organização no sistema nervoso reconhecendo símbolos, a recolocação de experiências passadas fazendo associações e produzindo significados para gerar uma resposta (consciente ou inconsciente) que é expressa para a outra pessoa.

- Tipos de comunicação não verbal. Explicação dos suportes utilizados para a emissão da comunicação não verbal e uma rápida exposição dos tipos de sinais não verbais: as ações ou movimentos do corpo, a postura corporal (cinésica), o toque (tacêsica), os sinais vocais ou paralinguísticos, o uso do espaço pelos comunicadores (proxêmica), os objetos e adornos utilizados, o tipo de corpo (características físicas) das pessoas envolvidas no processo de comunicação e o momento em que as palavras são ditas. Abordar, dentre os tipos de sinais não verbais, mais enfaticamente: a proxêmica (utilizando a classificação de $\mathrm{HALL}^{8}$, explicando o conceito de territoriedade, espaço pessoal, a distância íntima e suas características e os obstáculos físicos que dificultam a interação), a tacêsica (tipos de toque, aspectos envolvidos no tocar, situações estressantes e o toque afetivo), a cinésica (a orientação e inclinação do corpo nas interações, diferentes posturas e possíveis significados, gestos adaptadores e filtradores, a sincronia dos movimentos nas conversações), a relação direta entre as emoções e as expressões faciais (algumas emoções possíveis de serem detectadas pelo rosto e características e funções do olhar). Abordar o paraverbal apenas para reforçá-lo como sinal que. detecta dúvidas e ansiedade nos pacientes. exposição dialogada e exercício de percepção

\author{
exposição \\ dialogada e \\ exercícios \\ de \\ decodificação \\ de \\ emoções. \\ Os \\ exemplos \\ serão \\ retirados \\ da vivência \\ hospitalar \\ dos \\ participantes
}


- Funções da comunicação não verbal.

exposição Definir e exemplificar as funções: dialogada e complemento do verbal (qualquer sinal não verbal que tenha reforçado o que foi dito verbalmente), contradição do verbal (qualquer sinal não verbal que contradiga o que foi dito), substituição do verbal (qualquer sinal não verbal usado para substituir as palavras) e demonstração dos sentimentos (qualquer emoção demonstrada por outros meios que não as palavras). Reforçar que o não verbal retroalimenta e qualifica as interações.

- Fatores que interferem na percepção da comunicação não verbal do enfermeiro: conhecimento dos signos utilizados pelo paciente (a influência de sua história e cultura), dos meios empregados para a transmissão das mensagens, a situação e o momento onde o processo comunicativo está ocorrendo (ruídos), as expectativas, as emoções e estereótipos do enfermeiro, limitações físicas ou fisiológicas, as experiências vivenciadas por ele, a rotina do seu trabalho e tempo de estímulo apresentado.

- Desenvolvimento da percepção da comunicação não verbal pelo enfermeiro para que ele possa avaliar com maior precisão as mensagens enviadas pelo paciente, verificar a coerência dessas mensagens, detectar sua dificuldade em expor dúvida de forma verbal, demonstrar empatia e otimizar sua própria comunicação. Expor que o desenvolvimento da habilidade de emitir e receber (perceber e entender) sinais não verbais depende da sua motivação, atitude positiva, conhecimento dos sinais e experiência na sua percepção. Os recursos disponíveis para o desenvolvimento da percepção são: a vida diária, espelhos, fotografias, gravações, livros. Salientar que o registro desses sinais auxilia o enfermeiro a decodificar as emoções do paciente e sua evolução clínica. 
- Dramatizar situação de desinteresse do enfermeiro e dúvida e ansiedade no paciente.

- Filme com trecho de interação de enfermagem.
Dramatização

e discussão

Filme

demonstrativo

- Verificação de assimilação e sumarização do conteúdo.

\section{Avaliação do Programa}

A avaliação do programa deverá ser feita em dois momentos: um imediato pelas respostas a questionário que verifique a assimilação (contendo perguntas objetivas sobre o conteúdo e perguntas onde o participante possa aplicar o que ouviu) $^{\star \star \star}$ e, num segundo momento pela verificação, por meio de observação, da capacidade dos enfermeiros perceberem a comunicação não verbal dos pacientes em atendimento de enfermagem.

\section{CONSIDERAÇÕES FINAIS}

Considero que este artigo pode contribuir para alertar sobre a importância do ensino sistematizado da comunicação não verbal em enfermagem, como um dos fatores cruciais nas relações enfermeiro-paciente, além de propor, por meio de um programa, uma forma viável para sua aplicação.

Este estudo é um dos poucos que se dispõe iniciar a discussão sobre o treino e avaliação do ensino da comunicação não verbal. Face a enormidade de questionamentos possíveis nessa área, os resultados da implementação do presente programa, até o momento, podem ser encarados como um incentivo para outras pesquisas.

Seria aconselhável que diversas instituições verificassem o grau de percepção dos enfermeiros sobre a comunicação não verbal e implementassem o programa discutindo suas dificuldades e resultados.

\footnotetext{
*** Na tese de doutorado existe uma proposta de questionário de "verificação de assimilação"16
} 
A comunicação não verbal fala da essência dos indivíduos, de suas emoções e pensamentos. O desvendar de sua natureza potencializa a comunicação do enfermeiro com os pacientes e com sua equipe. Por que não utilizar programas rápidos, que despertem a motivação do enfermeiro para o assunto?

\section{GENERAL ASPECTS OF THE CONSTRUCTION OF A PROGRAM ABOUT NONVERBAL COMMUNICATION TO NURSES}

This study shows a program about nonverbal communication and is the continuation of a study of the failures in the perception of nonverbal communication in nurses who assist patients in nursing consultation. This study is one of the first to discuss the theme and describes the theoretical frameworks that legitimate its existence: LUFT \& INGHAM (1961); BIRDWHISTELL (1970); HALL (1976); STEINBERG (1988); SILVA (1989) and GAGNÉ (1980).

UNITERMS: communication; nonverbal communication

\section{ASPECTOS GENERALES DE LA CONSTRUCCIÓN DE UN PROGRAMA SOBRE LA COMUNICACIÓN NO VERBAL PARA ENFERMEROS}

Este trabajo presenta un programa sobre comunicación no verbal y es continuación de un estudio donde se verificaron fallas en la percepción de ese tipo de comunicación en los enfermeros que atendían pacientes en consultas de enfermería. Es uno de los primeros estudios que discute la temática de enseñaza de la comunicación no verbal en enfermería y justifica su montaje, describiendo rápidamente el referencial teórico que fundamentó su montaje: LUFT; INGHAM (1961) BIRDWHISTELL (1970); HALL (1976); STEINBERG (1988); SILVA (1989) y GAGNÉ (1980).

UNITERMOS: comunicación, comunicación no verbal 


\section{REFERÊNCIAS BIBLIOGRÁFICAS}

01. BIRDWHISTELL, R. L. Kinesics and contest. Philadelphia: Pennsylvania Press, 1970.

02. BLONDIS, M. N.; JACKSON, B. E. Nonverbal communication with patients: back to the human touch. New York: John Wiley, 1982. Cap. 1, p. 2-29: What is nonverbal communication?

03. CORAZE, J. As comunicações não verbais. Rio de janeiro: Zahar, 1982.

04. DAVIS, A. J. Listening and responding. Saint Louis: Mosby, 1984.

05. EDWARDS, B. J.; BRILHART, J. K. Communication in nursing practice. Saint Louis: Mosby, 1981. Cap. 3, p. 45-69: Nonverbal cues in nursing communication.

06. GAGNÉ, R. M. Como se realiza a aprendizagem. Rio de janeiro: L. T. C., 1976. 07. Princípios essenciais da aprendizagem para o ensino. Porto Alegre: Globo, 1980.

08. HALL, E. T. A dimensão oculta. Lisboa: Relógio D'água, 1986.

09. KRISTJANSON, L. T.; SCANLAN, J. M. Assessment of continuing nursing education needs: a literature review. J.Contin.Educ.Nurs., v. 20, n. 3, p. 11823,1989.

10. KRON, T. How we communicate nonverbally with patients. Can.Nurs., v. 68, n. 11 p. 21-6, 1972.

11. LUFT, J.; INGHAM, H. The johari window: a graphic model for interpersonal relations. Washington, Human Relations Training News, 1961.

12. PELÁ, N. T. R. et al. A educação em saúde na produção científica da pósgraduação da Escola de Enfermagem de Ribeirão Preto da Universidade de São Paulo. Enfoque, v. 17, n. 4, p. 93-6, 1989.

13. SANTAELLA, L. O que é semiótica. São Paulo: Brasiliense, 1987.

14. SILVA, M. J. P. A percepção das enfermeiras sobre a comunicação não verbal dos pacientes. São Paulo, 1989. p. 113. Dissertação (Mestrado) - Escola de Enfermagem, Universidade de São Paulo.

15. . Percebendo os sentimentos de maneira não verbal. Rev.Paul.Enfermagem, v. 10, n. 3, p. 128-32, 1991.

16. - Construção e validação de um programa sobre comunicação não verbal para enfermeiros. São Paulo, 1993. p. 108. Tese (Doutorado) -Escola de Enfermagem, Universidade de São Paulo.

17. SILVA, M. J. P. et al. Educação continuada: estratégia para o desenvolvimento do pessoal de enfermagem. Rio de janeiro: Marques Saraiva/EDUSP, 1989.

18. STEINBERG, M. Os elementos não verbais da conversação. São Paulo: Actual, 1988. 
19. VENINGA, R. Communications: a patient's eye view. Am.J.Nurs., v. 73, n. 1, p. 320-2, 1973.

20. WATZLAWICK, P. ET AL. Pragmática da comunicação humana. São Paulo: Cultrix, 1967. Cap. 2 p. 44-64: Alguns axiomas conjeturais de comunicação. 